\title{
Body Mass Index and Percentage Body Fat Determination in Cancer Patients
}

\author{
J. Owusu-Banahene ${ }^{1,2 *}$, E. O. Darko1,2, F. Hasford ${ }^{3}$ \\ ${ }^{1}$ Radiation Protection Institute, Ghana Atomic Energy Commission, Legon-Accra, Ghana \\ ${ }^{2}$ Graduate School of Nuclear and Allied Sciences, University of Ghana, Atomic Campus, Kwabenya-Accra, Ghana \\ ${ }^{3}$ Radiological and Medical Sciences Research Institute, Ghana Atomic Energy Commission, Legon-Accra, Ghana \\ Email: *owusubanas@yahoo.com
}

How to cite this paper: Owusu-Banahene, J., Darko, E.O. and Hasford, F. (2018) Body Mass Index and Percentage Body Fat Determination in Cancer Patients. Open Journal of Radiology, 8, 307-317. https://doi.org/10.4236/ojrad.2018.84034

Received: September 5, 2018

Accepted: December 26, 2018

Published: December 29, 2018

Copyright (c) 2018 by authors and Scientific Research Publishing Inc. This work is licensed under the Creative Commons Attribution International License (CC BY 4.0). http://creativecommons.org/licenses/by/4.0/

\begin{abstract}
Body Mass Index (BMI) and Percentage Body Fat (\%BF) values have been determined in cancer patients. In the study, 83 adult cancer patients were assessed of which 15 (18.1\%) were males and 68 (81.9\%) females. Body weight and height of individual patients were used in calculating their respective $\mathrm{BMI}$ values. The respective $\% \mathrm{BF}$ values were determined taking into consideration of the age, gender and BMI. Maximum values of BMI $\left(34.71 \mathrm{~kg} / \mathrm{m}^{2}\right)$ and $\% \mathrm{BF}$ (46.37\%) were obtained, for which they were females and the minimum values of BMI $\left(12.08 \mathrm{~kg} / \mathrm{m}^{2}\right)$ and $\% \mathrm{BF}(12.35 \%)$ respectively. The patient with the minimum $\% \mathrm{BF}$ value was male and that of BMI was female. It was observed from the results that females have higher values of both BMI and $\% \mathrm{BF}$ than their male counterparts. The study reveals higher rate of female cancer incidence than males.
\end{abstract}

\section{Keywords}

Body Mass Index, Percentage Body Fat, Obesity, Risk Factor and Metabolic Disorder

\section{Introduction}

Currently, cancer is one of the most deadly diseases in the world, killing about seven million people in the world every year for which about $70 \%$ of the deaths occur in developing countries. The number of cancer cases is growing globally but developing countries are worst hit by the cancer crisis, since the resources needed to prevent, diagnose and treatment are severely limited. It has been highlighted by Program of Action for Cancer Therapy (PACT) that these figures quoted for cancer rates are likely to double by the year 2020 and tripling nearly 
by the year 2030 with a projection of seventeen million deaths [1].

Obesity is a condition in which excess fat has accumulated in the body such that it may have an adverse effect on health leading to decreased life expectancy and increased health problems. Obesity and its related diseases are a major healthcare problem in many countries. The prevalence of obesity is increasing worldwide in both developed and developing countries. In the advanced countries like USA and Europe more than $40 \%$ of the population are overweight [2] [3]. Obesity is an important risk factor for many chronic diseases like diabetes mellitus, osteoarthritis, coronary heart disease, certain types of cancer like cancer of colon, nasopharyngeal and pregnancy complications. Obesity occurs as a person consumes more calories than one can burn. There are other factors which contribute to obesity development. Some of these are age, gender, physical activity and medication.

Changes in life styles and low physical activity even in developing societies is a predisposing factor for adult weight increasing and prevention of obesity is an important subject in health programming. Obese women appear to have greater iron stores than non-obese women [4]. Iron is an essential element and although deficiency leads to anemia, iron overload is also associated with many health problems [5]. Obesity is a metabolic disorder characterized by an increase of body fat. It is the degree of body fatness that is important as a risk factor rather than the degree of excess weight. However, the body fat cannot be measured easily. The World Health Organization (WHO) classification of obesity used BMI, a simple index of weight-of-height ratio, because of the robust nature of the measurements and routine inclusion of weight and height in clinical and population surveys [6]. The BMI is an index calculated from a person's weight and height. The BMI is a valuable tool which is used to determine whether a person's health is at risk or not.

Another way to determine whether one's weight is placing a health risk is to measure the circumference of your waist. Waist measurement does not determine if you are overweight, but it also an indication of having excess fat in the abdomen. This is important because, extra fat around the waist may increase health risks even more than fat elsewhere on the body. It has been established that women with waist measurements more than 35 inches $(88.9 \mathrm{~cm})$ and men with waist measurements more than 40 inches $(101.6 \mathrm{~cm})$ may have an increased risk for obesity-related diseases.

Determination of body mass index (BMI) is very important for cancer patients undergoing various types of radiotherapy. Body mass index is a measure of body weight relative to the height and it is consistently used as an estimate of adiposity. BMI has been positively associated with incidence and mortality from a variety of cancer patients [7] [8]. It is an indication whether the patient is underweight, normal, overweight or very overweight (obese). Obesity has more recently been shown to play a significant role in the development of some cancers, including cancers of the breast, prostate, colon and many others. Obesity increases the risk of certain types of cancers such as those involving the gastroin- 
testinal tract and hormone dependent neoplasms including endometrial carcinomas [8] [9]. Obese people are at a higher risk for developing failures in radiation therapy.

Patients can be classified into different BMI categories according to the WHO classification [10]. Category 1, acceptable (BMI $\left.<25 \mathrm{~kg} / \mathrm{m}^{2}\right)$; Category 2, overweight (BMI $\geq 25$ but $<30 \mathrm{~kg} / \mathrm{m}^{2}$ ); Category 3 , obese (BMI $\geq 30$ but $<40 \mathrm{~kg} / \mathrm{m}^{2}$ ); and Category 4, morbidly obese (BMI $\left.\geq 40 \mathrm{~kg} / \mathrm{m}^{2}\right)$. BMI is an important anthropometric index usually used for body fat status assessment and as an indicator for total body fat determination [11]. Deurenberg et al. [12] have established that the body fat can be determined for both children and adults.

A number of researchers have postulated that, fat tissues influence concentrations of various significant development signaling molecules, such as testosterone, estrogen and insulin-like growth factor, which play a vital role in cancer development and progression [12]. Different researchers have established different BMI limits for both men and women genders. This is very useful in either drug administration or delivering of radiation doses to cancer patients during treatment.

Cancer risk is associated with the metabolism of fats and sugars which affect hormones like insulin and estrogen. Estrogen affects the growth of cancer and normal cell proliferation. Excess fats in diet therefore create free radicals that can damage the cell membrane causing cells to become cancerous. Obese people have an abnormally high and unhealthy proportion of body fat. Research has shown that, the main causes of obesity are sedentary lifestyles and overconsumption of high calorie food [13] [14] [15]. Fruits and vegetables in diet contain phytochemicals that can neutralize excess free radicals and may reduce their toxic effects.

In this study, the $\mathrm{BMI}$ and \%BF would be investigated in relation to the high rate of incidence of cancer patients. The overall cancer patients would be categorized according to gender.

\section{Materials and Methods}

\subsection{Calculation of Body Mass Index}

The patient data were collected for 83 adults over a wide range of cancers. The cancer patients selected were all adults between the ages of 28 and 90 years with various types of cancer sites. Body weight was measured with light indoor clothing by an electronic balance with an accuracy of $0.1 \mathrm{~kg}$. Standing height without shoes was measured by a wall mounted stadiometer to the nearest $0.1 \mathrm{~cm}$. These measurements were taken while subjects were relaxed, standing erect and had their arms at their sides and feet together. The calculation of the BMI was done by using the golden standard formula as shown in Equation (1)

$$
B M I=\frac{W}{H^{2}}
$$

where: $W=$ weight of the patient in kilograms; $H=$ height in meters. 


\subsection{Calculation of Percentage Body Fat (\%BF)}

The calculations of the percentage body fat were determined by using the following mathematical equation for adult patients

$$
\begin{array}{r}
\text { Percentage Body fat }(\% \mathrm{BF})=(1.20 \times \mathrm{BMI})+ \\
(0.23 \times \text { Age }-(10.80 \times \text { gender })-5.4
\end{array}
$$

The rating for males and females gender was 1 and 0 respectively when applying the equation in (2).

For female adults, where by $\operatorname{Sex}=0$ it can be shown that, the equation becomes

$$
1.20 * \mathrm{BMI}+0.23 * \mathrm{Age}+5.4
$$

and for male adults, $\operatorname{Sex}=1$, then the equation also becomes

$$
1.20 * \mathrm{BMI}+0.23 * \text { Age }-16.2
$$

\section{Results and Discussion}

Table 1 shows the distribution of cancer patients with their calculated BMI and \%BF. In Table 1, it is observed that $22.9 \%$ were found to be overweight and obese according to the WHO classification using BMI as an index indicator for which mostly were females. The highest $\% \mathrm{BF}$ was $46.37 \%$ which was observed to be a female.

The variation of $\mathrm{BMI}$ and \%BF with the number of patients is shown in Figure 1 and Figure 2. From Figure 1, the maximum values of BMI and \%BF are

Table 1. Distribution of cancer patients with their calculated BMI and \%BF.

\begin{tabular}{ccccccc}
\hline Patient ID & Sex & Age (years) & Weight $(\mathrm{kg})$ & Height $(\mathrm{m})$ & BMI $\left(\mathrm{kg} / \mathrm{m}^{2}\right)$ & $\% \mathrm{BF}$ \\
\hline 001 & F & 45 & 39.7 & 1.58 & 15.90 & 24.03 \\
002 & F & 72 & 57.6 & 1.61 & 22.22 & 37.82 \\
003 & F & 43 & 69.7 & 1.65 & 25.76 & 35.40 \\
004 & M & 70 & 56.1 & 1.56 & 23.05 & 27.56 \\
005 & F & 64 & 57.2 & 1.73 & 19.11 & 32.25 \\
006 & F & 45 & 80.3 & 1.68 & 28.45 & 39.09 \\
007 & F & 62 & 46.8 & 1.53 & 19.99 & 32.85 \\
008 & F & 43 & 66.1 & 1.62 & 24.87 & 34.33 \\
009 & F & 54 & 55 & 1.59 & 21.75 & 33.12 \\
010 & F & 45 & 39.2 & 1.55 & 16.32 & 24.53 \\
011 & F & 64 & 32.5 & 1.58 & 13.02 & 24.94 \\
012 & M & 60 & 55 & 1.65 & 20.20 & 21.84 \\
013 & F & 38 & 67.2 & 1.64 & 24.99 & 33.33 \\
014 & F & 70 & 52.3 & 1.60 & 20.43 & 35.22 \\
015 & F & 72 & 48.6 & 1.59 & 19.22 & 34.22 \\
016 & F & 40 & 65.7 & 1.62 & 25.03 & 33.84 \\
017 & F & 50 & 57.8 & 1.58 & 23.30 & 34.06 \\
018 & F & 39 & 59.7 & 1.61 & 23.03 & 31.21 \\
019 & F & 41 & 69.9 & 1.69 & 24.39 & 33.30 \\
\hline
\end{tabular}




\section{Continued}

\begin{tabular}{|c|c|c|c|c|c|c|}
\hline 020 & $\mathrm{~F}$ & 44 & 93.8 & 1.64 & 34.71 & 46.37 \\
\hline 021 & $\mathrm{~F}$ & 73 & 48.5 & 1.50 & 21.56 & 37.26 \\
\hline 022 & $\mathrm{~F}$ & 75 & 53.6 & 1.63 & 20.17 & 36.05 \\
\hline 023 & $\mathrm{~F}$ & 75 & 51.6 & 1.61 & 19.91 & 35.74 \\
\hline 024 & $\mathrm{~F}$ & 71 & 57.8 & 1.61 & 22.30 & 37.69 \\
\hline 025 & $\mathrm{~F}$ & 32 & 62.5 & 1.73 & 20.88 & 27.02 \\
\hline 026 & $\mathrm{~F}$ & 75 & 37.7 & 1.60 & 14.7 & 29.49 \\
\hline 027 & F & 47 & 48.5 & 1.57 & 19.68 & 29.03 \\
\hline 028 & $\mathrm{~F}$ & 40 & 46.2 & 1.48 & 21.09 & 29.11 \\
\hline 029 & $\mathrm{~F}$ & 72 & 48.6 & 1.59 & 19.22 & 34.22 \\
\hline 030 & $\mathrm{~F}$ & 45 & 77.5 & 1.65 & 28.47 & 39.11 \\
\hline 031 & F & 40 & 65.7 & 1.62 & 25.03 & 33.84 \\
\hline 032 & $\mathrm{~F}$ & 75 & 32.8 & 1.55 & 13.65 & 28.23 \\
\hline 033 & $\mathrm{M}$ & 69 & 78.4 & 1.63 & 29.43 & 34.99 \\
\hline 034 & $\mathrm{~F}$ & 54 & 58.2 & 1.77 & 18.58 & 29.32 \\
\hline 035 & $\mathrm{M}$ & 31 & 62.4 & 1.61 & 24.07 & 19.81 \\
\hline 036 & $\mathrm{~F}$ & 60 & 53.5 & 1.57 & 21.71 & 34.45 \\
\hline 037 & $\mathrm{~F}$ & 65 & 48.6 & 1.66 & 17.64 & 30.72 \\
\hline 038 & $\mathrm{~F}$ & 55 & 69.3 & 1.71 & 23.70 & 35.69 \\
\hline 039 & F & 39 & 59.7 & 1.61 & 23.03 & 31.21 \\
\hline 040 & F & 43 & 61.7 & 1.65 & 22.66 & 31.68 \\
\hline 041 & $\mathrm{M}$ & 47 & 42.7 & 1.70 & 14.78 & 12.35 \\
\hline 042 & $\mathrm{~F}$ & 28 & 57.6 & 1.68 & 20.41 & 21.45 \\
\hline 043 & $\mathrm{~F}$ & 90 & 59.6 & 1.70 & 20.62 & 40.04 \\
\hline 044 & $\mathrm{~F}$ & 55 & 61.4 & 1.66 & 22.28 & 33.99 \\
\hline 045 & F & 64 & 32.5 & 1.64 & 12.08 & 23.82 \\
\hline 046 & $\mathrm{~F}$ & 75 & 70 & 1.58 & 28.04 & 45.50 \\
\hline 047 & F & 40 & 42.7 & 1.59 & 16.89 & 24.07 \\
\hline 048 & M & 69 & 55.8 & 1.60 & 21.80 & 25.83 \\
\hline 049 & $\mathrm{M}$ & 49 & 69.4 & 1.68 & 24.59 & 24.58 \\
\hline 050 & $\mathrm{~F}$ & 55 & 60.6 & 1.63 & 22.81 & 34.62 \\
\hline 051 & F & 74 & 56.7 & 1.67 & 20.33 & 36.02 \\
\hline 052 & F & 50 & 44 & 1.60 & 17.19 & 26.73 \\
\hline 053 & $\mathrm{~F}$ & 45 & 38.6 & 1.58 & 15.46 & 23.50 \\
\hline 054 & $\mathrm{M}$ & 70 & 60.6 & 1.79 & 18.91 & 22.59 \\
\hline 055 & $\mathrm{~F}$ & 61 & 64 & 1.72 & 21.63 & 34.59 \\
\hline 056 & $\mathrm{M}$ & 61 & 73.7 & 1.67 & 26.43 & 29.55 \\
\hline 057 & $\mathrm{~F}$ & 45 & 46.5 & 1.61 & 17.94 & 26.48 \\
\hline 058 & $\mathrm{M}$ & 61 & 93.0 & 1.66 & 33.75 & 38.33 \\
\hline 059 & F & 37 & 57.4 & 1.54 & 24.20 & 32.15 \\
\hline
\end{tabular}




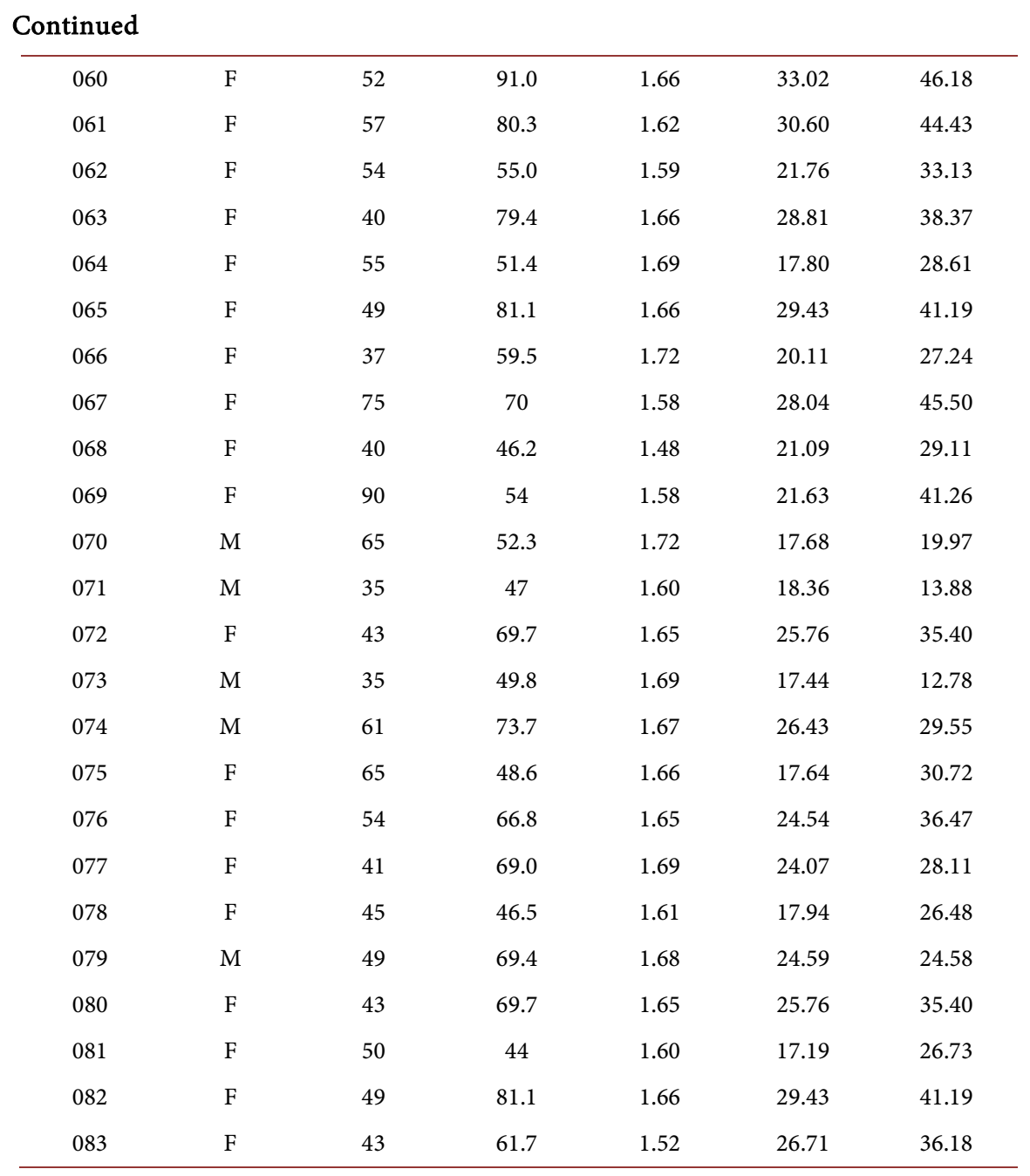

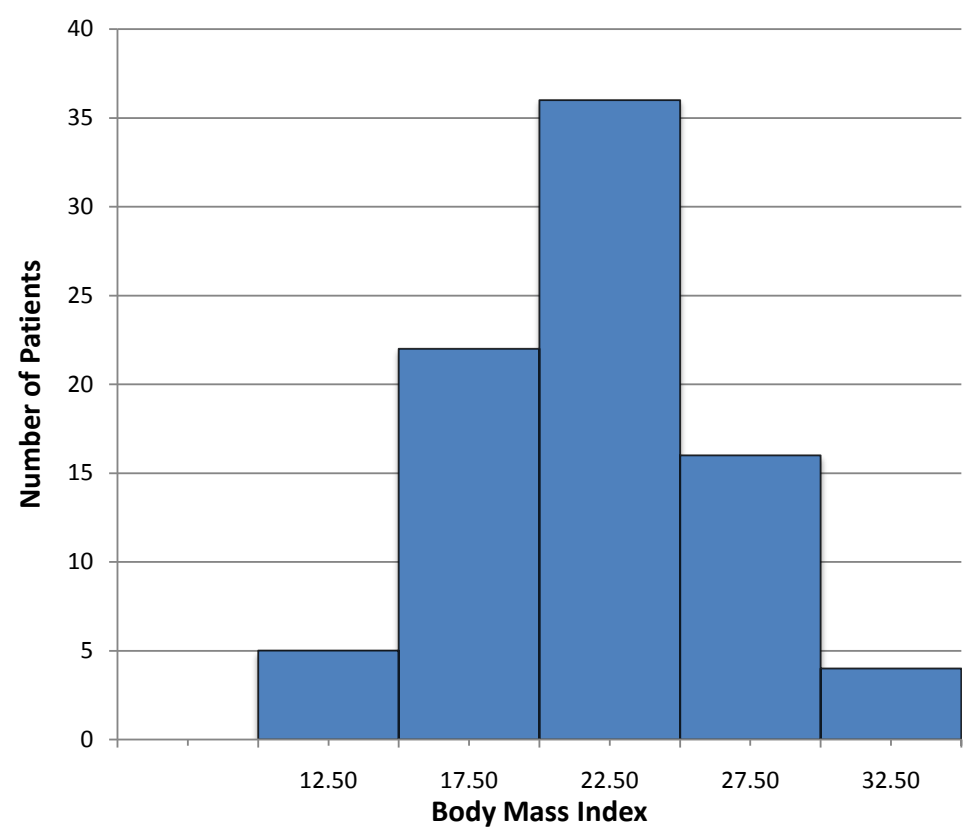

Figure 1. The distribution of BMI with number of patients. 


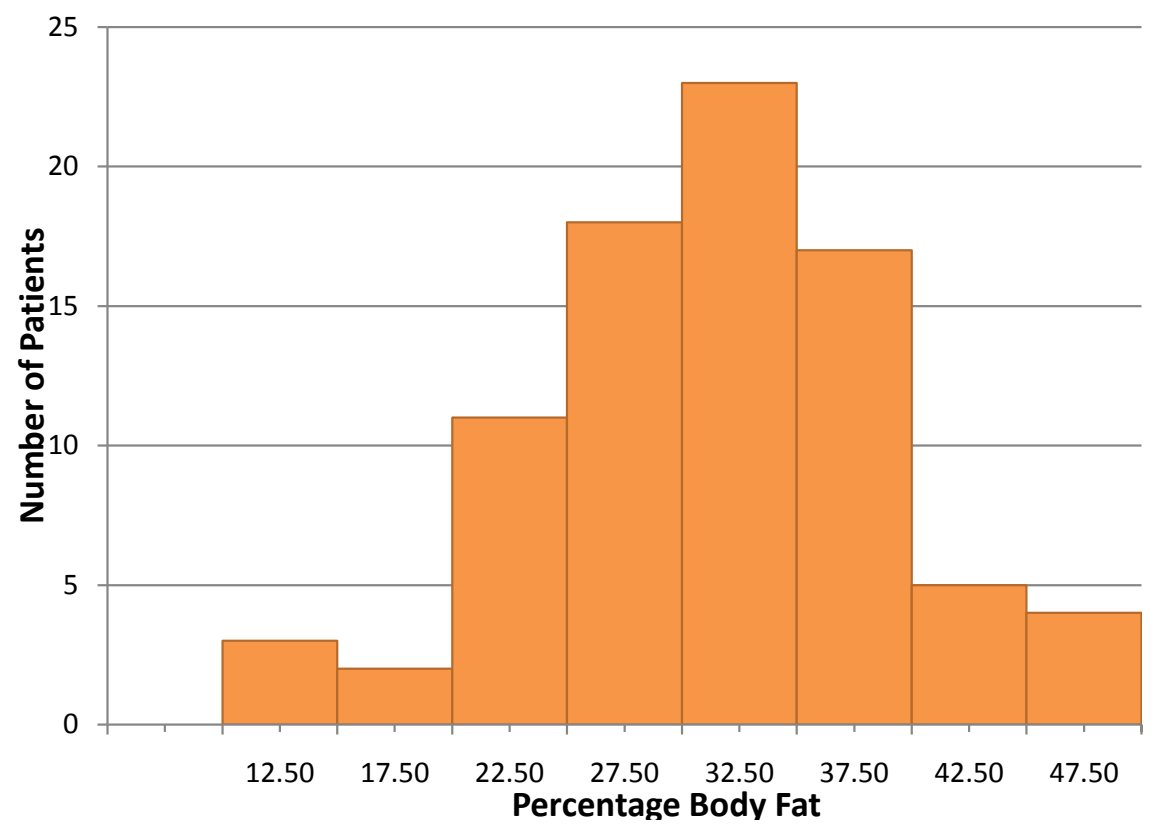

Figure 2. The distribution of percentage body fat with number of patients.

$34.71 \mathrm{~kg} / \mathrm{m}^{2}$ and 46.37 respectively, and this is seen in patients with identification number 020. Minimum values of BMI and \%BF however occurred in different patients. Patient ID Number 045 had the least BMI value of $12.08 \mathrm{~kg} / \mathrm{m}^{2}$, and patient ID Number 041 had the least \%BF value of 12.35. A general trend is observed in both $\mathrm{BMI}$ and \%BF for all other patients. In all patients, \%BF values are higher than BMI values except in only four patients with ID Numbers 035, 041, 071, and 073 for which they are all males. This could be as result of greater iron stores in females than in men [13]. The lowest \%BF value amongst the females is 21.45 and is seen in patient ID Number of 042. Figure 3 and Figure 4 also show the distribution of female and male patients in different age groups. From Figure 5, the patient parameters are age, weight, height, body mass index (BMI) and percentage body fat for both females and males. From Figure 5, it was observed that, the ages are almost the same or equal with slight difference in weight, height and body mass index (BMI) but there is remarkable difference in both males and females. From Figure 6, the patient parameters are compared with their corresponding age groups. It was seen that, the patient parameters follow the same trend having higher values for the weight, equal height, comparable BMI with gradual increase in their percentage body fats. The percentage patient distribution of BMI according to WHO classifications is also shown in Figure 7. In Figure 7, the series 1 have been removed from the pie chart. This shows the distribution in overweight, obese and acceptable percentage of BMI values according to the World Health Organization (WHO) classification. From Table 2, it is observed that, the distribution of cancer patients in terms of age group has the highest age group between 51 - 60 years however the lowest age group was observed between $71-80$ years. It was also observed that, the BMI values are almost equal. In Table 3, it was observed that, they have the same 


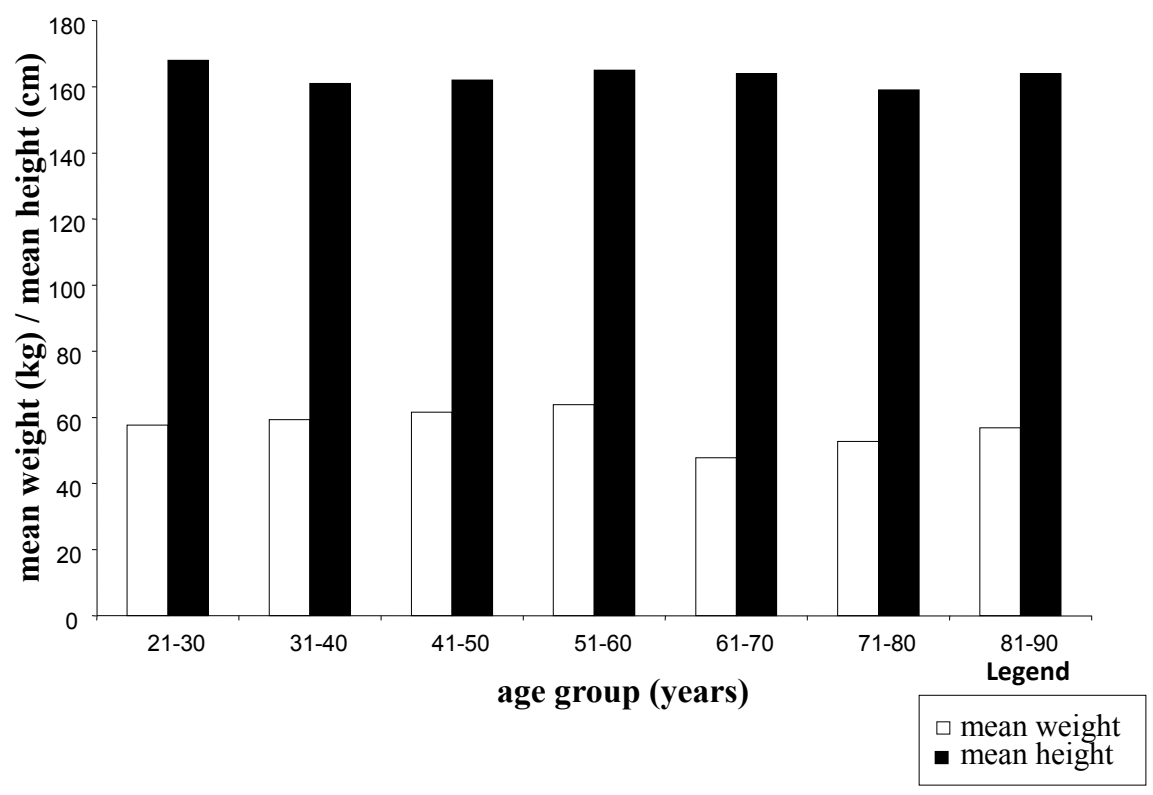

Figure 3. Distribution of female patients with age groups.

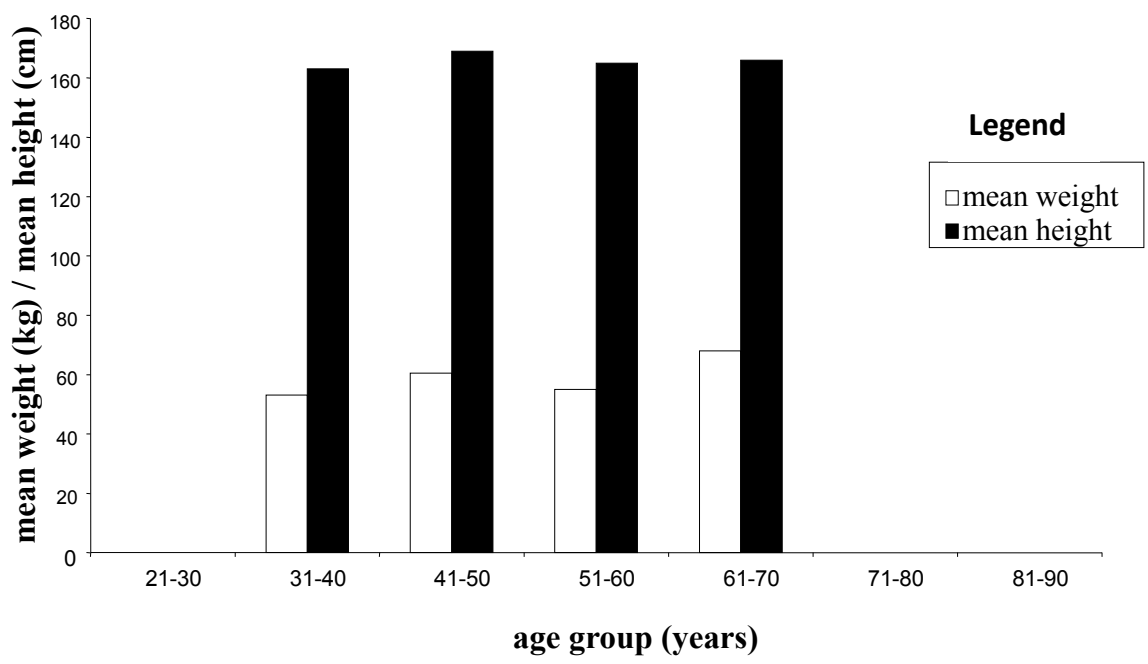

Figure 4. Distribution male patients with age groups.

Table 2. Distribution of cancer patients in terms of age group.

\begin{tabular}{ccccccccc}
\hline \multirow{2}{*}{$\begin{array}{c}\text { Age } \\
\text { group }\end{array}$} & \multicolumn{2}{c}{ Weight(kg) } & \multicolumn{2}{c}{ Height $(\mathrm{m})$} & \multicolumn{2}{c}{ BMI } & \multicolumn{2}{c}{$\%$ BF } \\
\cline { 2 - 9 } & Average & Range & Average & Range & Average & Range & Average & Range \\
\hline $21-30$ & 57.6 & 57.6 & 1.7 & 1.7 & 20.4 & 20.4 & 21.5 & 21.5 \\
$31-40$ & 59.7 & $46.2-79.4$ & 1.6 & $1.5-1.8$ & 22.6 & $17.4-28.8$ & 27.5 & $12.8-38.4$ \\
$41-50$ & 62.2 & $38.6-93.8$ & 1.6 & $1.5-1.7$ & 23.3 & $14.8-34.7$ & 31.4 & $12.4-46.4$ \\
$51-60$ & 64.0 & $51.4-91.0$ & 1.7 & $1.6-1.8$ & 23.4 & $17.8-33.0$ & 34.3 & $21.8-46.2$ \\
$61-70$ & 57.9 & $32.5-93.0$ & 1.7 & $1.5-1.8$ & 21.2 & $12.1-33.8$ & 29.6 & $20.0-38.3$ \\
$71-80$ & 52.8 & $32.8-70.0$ & 1.6 & $1.5-1.7$ & 20.8 & $13.7-28.0$ & 36.5 & $28.2-45.5$ \\
$81-90$ & 56.8 & $54.0-59.6$ & 1.6 & $1.6-1.7$ & 21.1 & $20.6-21.6$ & 40.7 & $40.0-41.3$ \\
\hline
\end{tabular}




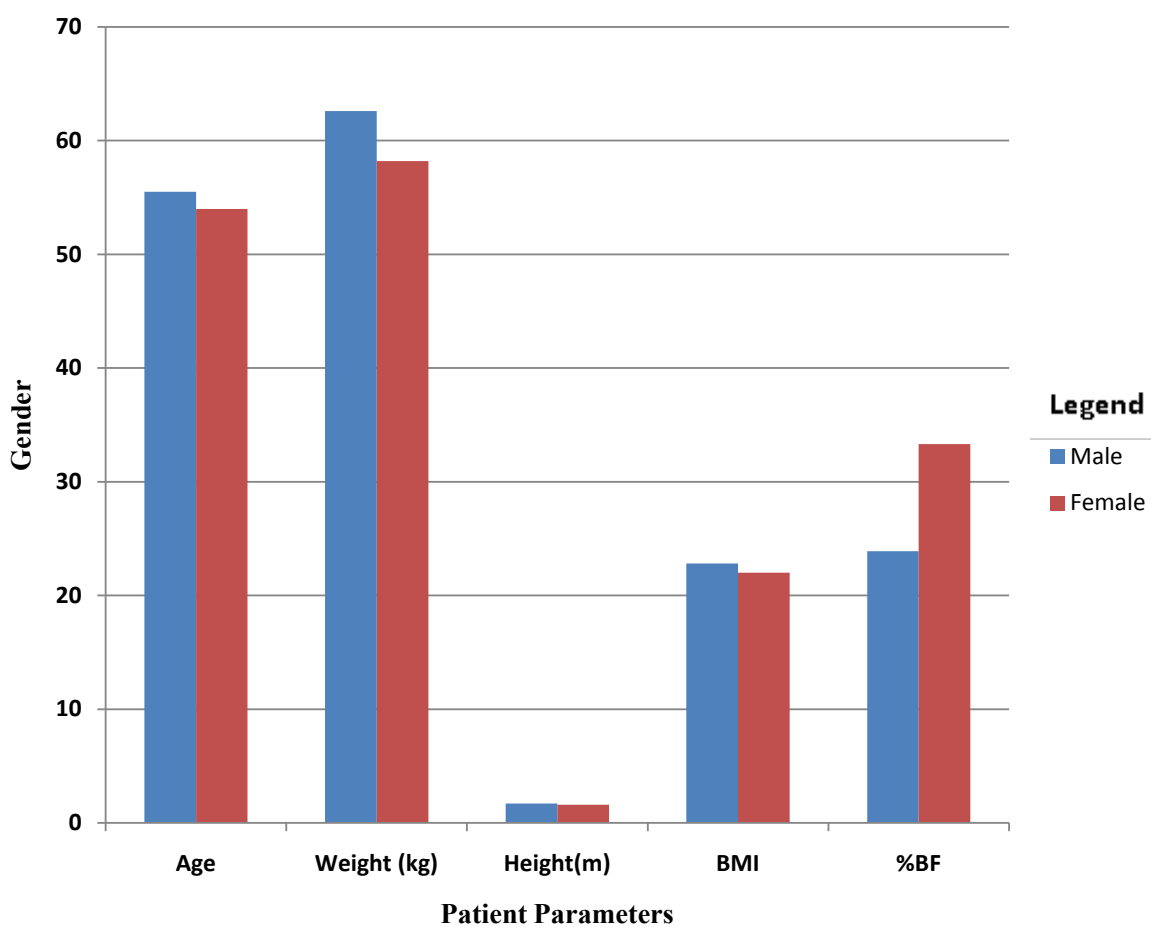

Figure 5. Distribution of patient parameters with gender.

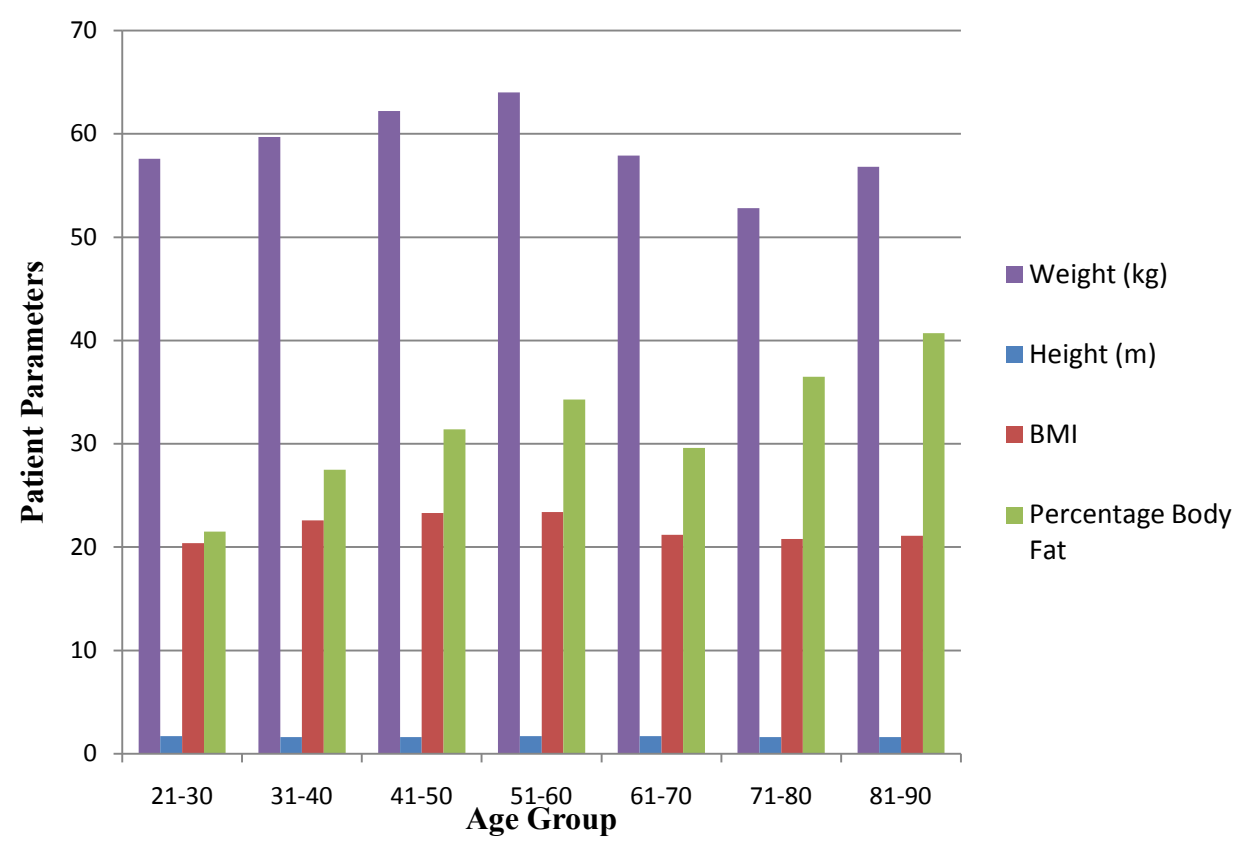

Figure 6. Distribution of patient parameters with age groups.

Table 3. Distribution of cancer patients in terms of gender.

\begin{tabular}{cccccccccccc}
\hline \multirow{2}{*}{ Sex } & \multirow{2}{*}{ No. } & \multicolumn{2}{c}{ Age } & \multicolumn{2}{c}{ Weight $(\mathrm{kg})$} & \multicolumn{2}{c}{ Height(m) } & \multicolumn{2}{c}{ BMI } & \multicolumn{2}{c}{$\% \mathrm{BF}$} \\
\cline { 2 - 11 } & & Average & Range & Average & Range & Average & Range & Average & Range & Average & Range \\
\hline M & 15 & 55.5 & $31-70$ & 62.6 & $42.7-93.0$ & 1.7 & $1.6-1.8$ & 22.8 & $14.8-33.8$ & 23.9 & $12.4-38.3$ \\
F & 68 & 54.0 & $28-90$ & 58.2 & $32.5-93.8$ & 1.6 & $1.5-1.8$ & 22.0 & $12.1-34.7$ & 33.3 & $21.5-46.4$ \\
\hline
\end{tabular}




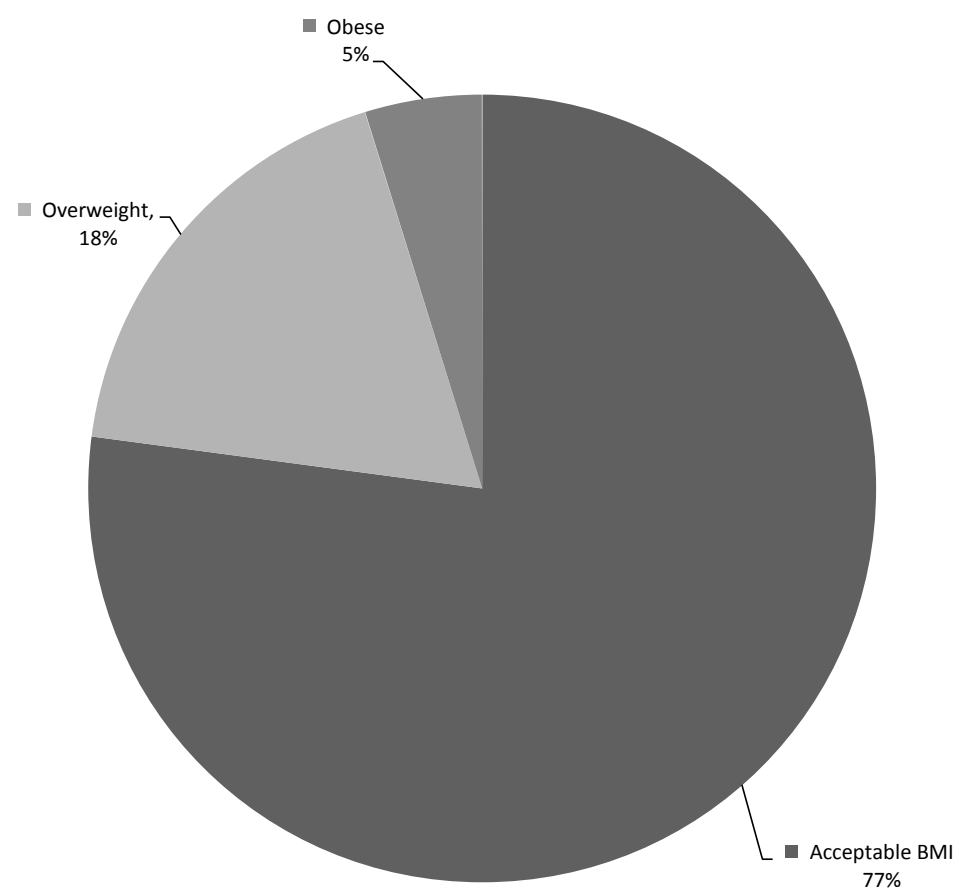

Figure 7. Percentage Patient distribution of BMI according to WHO classification.

height for both genders. Meanwhile there is remarkable difference in the percentage body fat $(\% \mathrm{BF})$ as females have higher $\% \mathrm{BF}$ than their male counterparts. However they have almost equal values of BMI.

\section{Conclusion}

In the study, the data of 83 adults aged from 28 to 90 years were analyzed and it has been observed that, females record high incidence of cancer than males (18.1\% females and $81.9 \%$ males). The results therefore suggest that females have higher values of $\% \mathrm{BF}$ than their male counterparts. From Figure 5 it can be deduced that females have much greater values of $\% \mathrm{BF}$ than their male counterparts even though their BMI values for both gender are comparable. The reasons for these high values might be due to low physical activities, much iron storage in females than males. It has been observed that, at the same BMI, women tend to have more body fat than men. Demographic study on cancer patients is being carried out to determine the location of the patient, quality of lifestyle and the daily nutritional aspects.

\section{Acknowledgements}

The authors would like to express their profound gratitude to the Oncology Unit at Komfo Anokye Teaching Hospital and the Radiation Protection Institute for the use of their facilities for the study.

\section{Conflicts of Interest}

The authors declare no conflicts of interest regarding the publication of this paper. 


\section{References}

[1] (2010) IAEA, International Atomic Energy Agency Bulletin, 51, 6-7.

[2] Seidel, J.C. (2000) Obesity, Insulin Resistance and Diabetes-A Worldwide Epidemic. British Journal of Nutrition, 83, S5-S8. https://doi.org/10.1017/S000711450000088X

[3] Hodge, A.M and Zimmet, P.Z. (1994) The Epidemiology of Obesity. Baillière's Clinical Endocrinology and Metabolism, 8, 577-599.

[4] Fricker, J., Moel, G.L. and Apfelbau, M. (1990) Obesity and Iron Status in Menstruating Women. The American Journal of Clinical Nutrition, 52, 863-866. https://doi.org/10.1093/ajcn/52.5.863

[5] John, B.W., Susan, T., Gu, Z., Lawrie, W.P. and Nicholas, G.M. (2003) Relative Importance of Female Specific Effects on Variation in Iron Stores between Women. British Journal of Haematology, 120, 860-866.

[6] World Health Organisation (1997) Obesity, Prevention and Managing the Global epidemic. Report on a WHO Consultation on Obesity. Geneva.

[7] International Agency for Research on Cancer. (2002) IARC Handbooks of Cancer Prevention. Weight Control and Physical Activity. IACR, Lyon, 83-133.

[8] Calle, E.E., Rodriguez, C., Walker-Thumond, K. and Thun, M.J. (2003) Overweight, Obesity and Mortality from Cancer in a Prospectively Studied Cohort of USA Adults. New England Journal of Medicine, 348, 1625-1638. https://doi.org/10.1056/NEJMoa021423

[9] Johnson, F., Wolk, A., Pedersen, N.L., et al. (2003) Obesity and Hormone-Dependent Tumours; Cohort and Co-Twin Control Studies Based on the Swedish Twin Registry. International Journal of Cancer, 106, 594-599. https://doi.org/10.1002/ijc.11266

[10] Mydlo, J.H., Tieng, N.L., Volpe, M.A., Chaiken, R. and Kral, J.G. (2001) A Pilot Study Analyzing PSA, Serum Testosterone, Lipid Profile, Body Mass Index and Race in a Small Sample of Patients with and without Carcinoma of the Prostate. Prostate Cancer and Prostatic Diseases, 4, 101-105. https://doi.org/10.1038/sj.pcan.4500514

[11] Jackson, A.S., Stanforth, P.R., Gagnon, J., et al. (2002) The Effect of Sex, Age and Race on Estimating Percentage Body Fat from BMI; The Heritage Family Study. International Journal of Obesity, 26, 789-796. https://doi.org/10.1038/sj.ijo.0802006

[12] Deurenderg, P., Westrate, J.A and Seidel, J.C. (1991) Body Mass Index as a Measure of Body Fatness; Age and Sex Specific Prediction Formulas. British Journal of $\mathrm{Nu}$ trition, 65, 105-114. https://doi.org/10.1079/BJN19910073

[13] Liengsawangwong, R., Sun, T., Yu, T., Erasmus, J., Perkins, G., Tereffe, W., Oh, J., Woodward, W., Strom, E. and Salephour, M. (year) International Journal of Radiation Oncology Biology Physics, 69, 711-715.

[14] Feigelson, H.S., Jonas, C.R., Teras, L.R., Thun, M.J. and Calle, E.E. (2004) Weight Gain, Body Mass Index, Hormone Replacement Therapy, and Post-Menopausal Breast Cancer in a Large Prospective Study. Cancer Epidemiology, Biomarkers \& Prevention, 13, 220-224. https://doi.org/10.1158/1055-9965.EPI-03-0301

[15] Friedenreich, C.M. (2001) Physical Activity and Cancer Prevention. From Observational Intervention Research. Cancer Epidemiology, Biomarkers and Prevention, 10, 287-301. 